IP Periodica Polytechnica Civil Engineering

59(1), pp. 5963 2015

DOI: $10.3311 /$ PPci.7753

Creative Commons Attribution $($ )

RESEARCH ARTICLE

\section{Alternative Method to Determine the Characteristic Polynomial Applying Three-by-Three Matrices}

\author{
Csaba Budai, Brigitta Szilágyi
}

Received 14-10-2014, revised 21-11-2014, accepted 08-12-2014

\begin{abstract}
The main aim of this paper is the presentation of the connection between the elements of the classical matrix arithmetic in case of three-by-three arbitrary real matrices. The given formulae can be used as well in case of the topic of stability analysis connected to the characteristic polynomial. The theorems and formulae presented in this article can be used in linear algebra courses or e.g. in three Degrees-of-Freedom mechanical problems, in machine tool bases designing, or in analyzes of earthquake effect on different type of structures.
\end{abstract}

\section{Keywords}

matrix operators $\cdot$ three-by-three matrices $\cdot$ characteristic polynomial

\section{Csaba Budai}

Department of Mechatronics, Optics and Mechanical Engineering Informatics, Faculty of Mechanical Engineering, Budapest University of Technology and Economics, Múegyetem rkp. 3, H-1111 Budapest, Hungary

e-mail: budaicsaba@mogi.bme.hu

\section{Brigitta Szilágyi}

Department of Geometry, Institute of Mathematics, Faculty of Natural Sciences, Budapest University of Technology and Economics, Múegyetem rkp. 3, H-1111 Budapest, Hungary

e-mail: szilagyi@math.bme.hu

\section{Acknowledgement}

The project presented in this article is supported by the Hungarian National Science Foundation under grant no. OTKA K112506.

\section{Introduction}

At the beginning of the Linear Algebra courses in bachelor mechanical engineering studies the definitions of the determinant and the adjugate operations are introduced, but the definition of the trace operation is introduced in general at the end of the semester, sometimes it is thought after the Analysis of the Multiple Variables Functions. Therefore the examples for the calculations of the different type of determinant can be found in a lot of books with practical examples, where we can also found some solution of problems with interesting tips for the solution method. Otherwise the nice formulae between the determinant, trace and adjugate almost nowhere can be found.

The engineering applications or solutions the engineering problems cannot adjust the series of the mathematical semesters. Sometimes it cannot follow the structure of the mathematical semesters, because some necessary mathematical knowledge has to be thought by engineers on some engineering courses keeping the "rhythmical" progress in case of teaching the engineering knowledge.

The basic mechanical courses use many different type of mathematics (e.g. Single Variable Function Analysis, Ordinary Differential Equations or Basic and Linear Algebra), where the necessary mathematics has to be thought earlier than in the mathematics courses thought it. In case of vibrations problems the derivation of the coefficients of the characteristic polynomial can be "complicated". However if the presented formulae are used, this process can be "easier".

The introduced formulae are appropriate, that in the Analysis and Linear Algebra courses the concept of determinant, trace and adjugate expressions can be thought more deep and more extensively, and the formulae could be great examples in the practice courses. These formulae can be shown for the students as a provable expression; therefore the students can be learning this expression easier. 
On the other hand, the presented formulae below can be applied also in mechanical and civil engineering practice in problems of designed structures against dynamical effect. These formulae can be also a quite good technique to analyse in different topics of machining [1, 2], particularly design of machine bases, examining the earthquake effect [3, 4], impacting models between moving structures and rigid walls, or effects of periodically excitation on structures [5].

Based on many textbook [6-10], identities in matrix operations are known only for constant, or matrix multiplied matrices, but identities for sum of matrices are already missing expected the trace operation. In our previous work [11,12] identities in case of two-by-two matrices are presented. In this paper we focus on the identities of three-by-three matrices compared to the two-by-two cases.

In this paper vectors and matrices are denoted by bold letters. The matrix elements are denoted by small letters. Determinant, trace and adjoint operators are denoted by det (.), $\operatorname{tr}($.$) and \operatorname{adj}($. respectively.

\section{Matrix operation identities of sum three-by-three ma- trices}

Theorem 1 - Matrices A and $\mathbf{B}$ are real element, three-bythree matrices. The identity of determinant of matrix sum in closed form is

$$
\begin{aligned}
& \operatorname{det}(\mathbf{A}+\mathbf{B})=\operatorname{det}(\mathbf{A})+\operatorname{det}(\mathbf{B})+ \\
& \operatorname{tr}(\mathbf{A} \operatorname{adj}(\mathbf{B}))+\operatorname{tr}(\mathbf{B} \operatorname{adj}(\mathbf{A})) .
\end{aligned}
$$

Prof of Theorem 1 - By expanding the determinant of matrix sum, the left-hand-side of Eq. (1) becomes

$$
\begin{aligned}
\operatorname{det}(\mathbf{A}+\mathbf{B}) & =\left(a_{11}+b_{11}\right)\left(a_{22}+b_{22}\right)\left(a_{33}+b_{33}\right) \\
& -\left(a_{11}+b_{11}\right)\left(a_{23}+b_{23}\right)\left(a_{32}+b_{32}\right) \\
& -\left(a_{12}+b_{12}\right)\left(a_{21}+b_{21}\right)\left(a_{33}+b_{33}\right) \\
& +\left(a_{12}+b_{12}\right)\left(a_{23}+b_{23}\right)\left(a_{31}+b_{31}\right) \\
& +\left(a_{13}+b_{13}\right)\left(a_{21}+b_{21}\right)\left(a_{32}+b_{32}\right) \\
& -\left(a_{13}+b_{13}\right)\left(a_{22}+b_{22}\right)\left(a_{31}+b_{31}\right)
\end{aligned}
$$

By expanding the containing terms of the right-hand-side of Eq. (1), the elements are

$$
\begin{aligned}
\operatorname{det}(\mathbf{A}) & =a_{11}\left(a_{22} a_{33}-a_{23} a_{32}\right) \\
& -a_{12}\left(a_{21} a_{33}-a_{23} a_{31}\right) \\
& +a_{13}\left(a_{21} a_{32}-a_{22} a_{31}\right) \\
\operatorname{det}(\mathbf{B}) & =b_{11}\left(b_{22} b_{33}-b_{23} b_{32}\right) \\
& -b_{12}\left(b_{21} b_{33}-b_{23} b_{31}\right) \\
& +b_{13}\left(b_{21} b_{32}-b_{22} b_{31}\right)
\end{aligned}
$$

$$
\begin{aligned}
& \operatorname{tr}(\mathbf{A} \operatorname{adj}(\mathbf{B}))= \\
& a_{11}\left(b_{22} b_{33}-b_{23} b_{32}\right) \\
& +a_{12}\left(-b_{21} b_{33}+b_{23} b_{31}\right)+a_{13}\left(b_{21} b_{32}-b_{22} b_{31}\right) \\
& +a_{21}\left(-b_{12} b_{33}+b_{32} b_{13}\right)+a_{22}\left(b_{11} b_{33}-b_{13} b_{31}\right) \\
& +a_{23}\left(-b_{11} b_{32}+b_{12} b_{31}\right)+a_{31}\left(b_{12} b_{23}-b_{13} b_{22}\right) \\
& +a_{32}\left(-b_{11} b_{23}+b_{13} b_{21}\right)+a_{33}\left(b_{11} b_{22}-b_{12} b_{21}\right) \\
& \operatorname{tr}(\mathbf{B} \operatorname{adj}(\mathbf{A}))=b_{11}\left(a_{22} a_{33}-a_{23} a_{32}\right) \\
& +b_{12}\left(-a_{21} a_{33}+a_{23} a_{31}\right)+b_{13}\left(a_{21} a_{32}-a_{22} a_{31}\right) \\
& +b_{21}\left(-a_{12} a_{33}+a_{32} a_{13}\right)+b_{22}\left(a_{11} a_{33}-a_{13} a_{31}\right) \\
& +b_{23}\left(-a_{11} a_{32}+a_{12} a_{31}\right)+b_{31}\left(a_{12} a_{23}-a_{13} a_{22}\right) \\
& +b_{32}\left(-a_{11} a_{23}+a_{13} a_{21}\right)+b_{33}\left(a_{11} a_{22}-a_{12} a_{21}\right)
\end{aligned}
$$

If we expand left-hand-side in Eq. (1), it is equal to sum of Eqs. (3) - 6), therefore the Theorem 1 is true.

It can be seen if the presented formula in Theorem 1 is compared to the two-by-two case, that $\operatorname{tr}(\mathbf{A} \operatorname{adj}(\mathbf{B})) \neq \operatorname{tr}(\mathbf{B} \operatorname{adj}(\mathbf{A}))$. It follows, only the two-by-two matrices has that special property $\operatorname{tr}(\mathbf{A} \operatorname{adj}(\mathbf{B}))=\operatorname{tr}(\mathbf{B} \operatorname{adj}(\mathbf{A}))$.

Theorem 2 - Matrices $\mathbf{A}$ and $\mathbf{B}$ are real element, three-bythree matrices. The identity of adjugate of matrix sum in closed form

$$
\operatorname{adj}(\mathbf{A}+\mathbf{B})=\operatorname{adj}(\mathbf{A})+\operatorname{adj}(\mathbf{B})+\mathbf{L}^{\mathrm{T}} .
$$

In Eq. (7) matrix $\mathbf{L}$ can be determined as

$$
l_{i j}=(-1)^{i+j} \operatorname{tr}\left(\operatorname{adj}\left(\mathbf{A}_{i j}\right) \mathbf{B}_{i j}\right),
$$

where $i, j=1,2,3$ and $\mathbf{A}_{i j}, \mathbf{B}_{i j}$ are the minor matrices of $\mathbf{A}$ and $\mathbf{B}$.

Proof of Theorem 2 - Let us define matrix $\mathbf{R}$ as $\mathbf{R}=\operatorname{adj}(\mathbf{A}+$ B) $-\operatorname{adj}(\mathbf{A})-\operatorname{adj}(\mathbf{B})$. We will present the method of proven to the element $r_{11}$ and $r_{21}$ of matrix $\mathbf{R}$.

The element $r_{11}$ can be calculated as $r_{11}=a_{22} b_{33}-a_{23} b_{32}-$ $a_{32} b_{23}+a_{33} b_{22}$. Based on Eq. (8) in Theorem $2 l_{11}$ can be determined

$$
l_{11}=(-1)^{1+1} \operatorname{tr}\left(\operatorname{adj}\left(\mathbf{A}_{11}\right) \mathbf{B}_{11}\right)=\operatorname{tr}\left(\operatorname{adj}\left(\mathbf{A}_{11}\right) \mathbf{B}_{11}\right)
$$

where

$$
\mathbf{A}_{11}=\left[\begin{array}{ll}
a_{22} & a_{23} \\
a_{32} & a_{33}
\end{array}\right] \text { and } \mathbf{B}_{11}=\left[\begin{array}{ll}
b_{22} & b_{23} \\
b_{32} & b_{33}
\end{array}\right]
$$

We obtain

$$
l_{11}=a_{22} b_{33}-a_{23} b_{32}-a_{32} b_{23}+a_{33} b_{22},
$$

It can be seen, that $r_{11}=l_{11}$. 
The element $r_{21}$ can be calculated as $r_{21}=-\left(a_{21} b_{33}-\right.$ $\left.a_{23} b_{31}-a_{31} b_{23}+a_{33} b_{21}\right)$. Based on Eq. (8) in Theorem $2 l_{12}$ can be determined

$$
l_{12}=-\operatorname{tr}\left(\operatorname{adj}\left(\mathbf{A}_{12}\right) \mathbf{B}_{12}\right) \text {, }
$$

where

$$
\mathbf{A}_{12}=\left[\begin{array}{ll}
a_{21} & a_{23} \\
a_{31} & a_{33}
\end{array}\right] \text { and } \mathbf{B}_{12}=\left[\begin{array}{ll}
b_{21} & b_{23} \\
b_{31} & b_{33}
\end{array}\right] .
$$

We obtain

$$
l_{12}=-\left(a_{21} b_{33}-a_{23} b_{31}-a_{31} b_{23}+a_{33} b_{21}\right),
$$

It can be seen, that $r_{21}=l_{12}$. If this presented method above is applied to the other elements of matrix $\mathbf{R}$, it can be seen, that all elements are equal to each other, therefore the Theorem 2 is true.

Consequence 1 - Matrices A, B and $\mathbf{C}$ are real element, threeby-three arbitrary real matrices. Let denote matrix $\mathbf{L}$ (in Eq. (8)) as $\mathbf{L}_{A B}$. The determinant of the sum of matrices can be also given in closed form, i.e.

$$
\begin{aligned}
& \operatorname{det}(\mathbf{A}+\mathbf{B}+\mathbf{C})=\operatorname{det}(\mathbf{A})+\operatorname{det}(\mathbf{B}) \\
& +\operatorname{det}(\mathbf{C})+\operatorname{tr}(\mathbf{A} \operatorname{adj}(\mathbf{B}))+\operatorname{tr}(\mathbf{B} \operatorname{adj}(\mathbf{A})) \\
& +\operatorname{tr}(\mathbf{A} \operatorname{adj}(\mathbf{C}))+\operatorname{tr}(\mathbf{C} \operatorname{adj}(\mathbf{A})) \\
& +\operatorname{tr}(\mathbf{C} \operatorname{adj}(\mathbf{B}))+\operatorname{tr}(\mathbf{B} \operatorname{adj}(\mathbf{C}))+\operatorname{tr}\left(\mathbf{C L}_{A B}^{\mathrm{T}}\right) .
\end{aligned}
$$

Because of the left-hand-side of Eq. (13), $\operatorname{det}(\mathbf{A}+\mathbf{B}+\mathbf{C})$ can be look as $\operatorname{det}((\mathbf{A}+\mathbf{B})+\mathbf{C})$, then Theorem 1 can apply, therefore

$$
\begin{aligned}
& \operatorname{det}(\mathbf{A}+\mathbf{B}+\mathbf{C})=\operatorname{det}(\mathbf{A}+\mathbf{B})+\operatorname{det}(\mathbf{C}) \\
& +\operatorname{tr}((\mathbf{A}+\mathbf{B}) \operatorname{adj}(\mathbf{C}))+\operatorname{tr}(\mathbf{C} \operatorname{adj}(\mathbf{A}+\mathbf{B}))
\end{aligned}
$$

Applying Theorem 1 again, we get

$$
\begin{aligned}
& \operatorname{det}((\mathbf{A}+\mathbf{B})+\mathbf{C})=\operatorname{det}(\mathbf{A})+\operatorname{det}(\mathbf{B})+ \\
& \operatorname{tr}(\mathbf{A} \operatorname{adj}(\mathbf{B}))+\operatorname{tr}(\mathbf{B} \operatorname{adj}(\mathbf{A}))+\operatorname{det}(\mathbf{C}) \\
& +\operatorname{tr}((\mathbf{A}+\mathbf{B}) \operatorname{adj}(\mathbf{C})) \\
& +\operatorname{tr}(\mathbf{C} \operatorname{adj}(\mathbf{A}+\mathbf{B})),
\end{aligned}
$$

because of $\operatorname{tr}(\mathbf{A}+\mathbf{B})=\operatorname{tr}(\mathbf{A})+\operatorname{tr}(\mathbf{B})$, Eq. 15] becomes

$$
\begin{aligned}
& \operatorname{det}((\mathbf{A}+\mathbf{B})+\mathbf{C})=\operatorname{det}(\mathbf{A})+\operatorname{det}(\mathbf{B}) \\
& +\operatorname{tr}(\mathbf{A} \operatorname{adj}(\mathbf{B}))+\operatorname{tr}(\mathbf{B} \operatorname{adj}(\mathbf{A}))+\operatorname{det}(\mathbf{C}) \\
& +\operatorname{tr}(\mathbf{A} \operatorname{adj}(\mathbf{C}))+\operatorname{tr}(\mathbf{B} \operatorname{adj}(\mathbf{C})) \\
& +\operatorname{tr}(\mathbf{C} \operatorname{adj}(\mathbf{A}+\mathbf{B})) .
\end{aligned}
$$

Finally, if we apply Theorem 2, we get the following identity

$$
\begin{aligned}
& \operatorname{det}(\mathbf{A}+\mathbf{B}+\mathbf{C})=\operatorname{det}(\mathbf{A})+\operatorname{det}(\mathbf{B}) \\
& +\operatorname{det}(\mathbf{C})+\operatorname{tr}(\mathbf{A} \operatorname{adj}(\mathbf{B}))+\operatorname{tr}(\mathbf{B} \operatorname{adj}(\mathbf{A})) \\
& +\operatorname{tr}(\mathbf{A} \operatorname{adj}(\mathbf{C}))+\operatorname{tr}(\mathbf{C} \operatorname{adj}(\mathbf{A})) \\
& +\operatorname{tr}(\mathbf{C} \operatorname{adj}(\mathbf{B}))+\operatorname{tr}(\mathbf{B} \operatorname{adj}(\mathbf{C})) \\
& +\operatorname{tr}\left(\mathbf{C L}_{A B}^{\mathrm{T}}\right) .
\end{aligned}
$$

As we mentioned above, elements of matrix $\mathbf{L}_{A B}$ can be determined as $l_{A B, i j}=(-1)^{i+j} \operatorname{tr}\left(\operatorname{adj}\left(\mathbf{A}_{i j}\right) \mathbf{B}_{i j}\right)$. In case, when three matrix are in the formula, we can also define element $l_{B C, i j}$ as $l_{B C, i j}=(-1)^{i+j} \operatorname{tr}\left(\operatorname{adj}\left(\mathbf{C}_{i j}\right) \mathbf{B}_{i j}\right)$, and element $l_{A C, i j}$ as $l_{A C, i j}=(-1)^{i+j} \operatorname{tr}\left(\operatorname{adj}\left(\mathbf{C}_{i j}\right) \mathbf{A}_{i j}\right)$. We could say a new theorem.

Theorem 3 - Matrices $\mathbf{A}, \mathbf{B}$ and $\mathbf{C}$ are real element, three-bythree arbitrary real matrices.

$$
\operatorname{tr}\left(\mathbf{A} \mathbf{L}_{B C}^{\mathrm{T}}\right)=\operatorname{tr}\left(\mathbf{B} \mathbf{L}_{A C}^{\mathrm{T}}\right)=\operatorname{tr}\left(\mathbf{C} \mathbf{L}_{A B}^{\mathrm{T}}\right)
$$

Prof of Theorem 3 - Similar method can be used to prove Theorem 3 like in case of Prof of Theorem 2. In this case because of the much number of elements the detailed calculation is not presented. However if we compare the sum of the elements of the main diagonal of the matrices, it can be seen, that the elements are equal to each other, therefore this Theorem 3 is also true.

\section{Characteristic polynomial using three-by-three matri- ces}

Based on Theorem 1, or Consequence 1, the characteristic polynomial can be derived in a closed form. Let us consider the second-order homogeneous differential equation with matrix coefficient in the form

$$
\mathbf{A} \ddot{\mathbf{q}}+\mathbf{B} \dot{\mathbf{q}}+\mathbf{C q}=\mathbf{0}
$$

In Eq. (19) matrices $\mathbf{A}, \mathbf{B}, \mathbf{C}$ are real element threedimensional quadratic matrices, and $\mathbf{q}: \mathbb{R} \rightarrow \mathbb{R}^{3}$. The following notations are introduced: $\mathbf{q}:=\mathbf{q}(t), \mathbf{q}:=\mathrm{d} \mathbf{q}(t) / \mathrm{d} t$ and $\ddot{\mathbf{q}}:=\mathrm{d}^{2} \mathbf{q}(t) / \mathrm{d} t^{2}$.

In applied mechanics, matrices $\mathbf{A}, \mathbf{B}, \mathbf{C}$ are called mass or inertia, viscous damping and stiffness matrices respectively (usually they are denoted by matrices $\mathbf{M}, \mathbf{K}, \mathbf{S}$ ). The vector $\mathbf{q}$ is the so-called vector of generalized coordinates, and $t$ denotes the time [13]. During derivation of characteristic polynomial the following identities are used $\operatorname{det}(\lambda \mathbf{A})=\lambda^{3} \operatorname{det}(\mathbf{A}), \operatorname{adj}(\lambda \mathbf{A})=$ $\lambda^{2} \operatorname{adj}(\mathbf{A})$ and $\operatorname{tr}(\lambda \mathbf{A})=\lambda \operatorname{tr}(\mathbf{A})$. The characteristic polynomial of Eq. [19] is

$$
p(\lambda)=\operatorname{det}\left(\lambda^{2} \mathbf{A}+\lambda \mathbf{B}+\mathbf{C}\right) .
$$

The following steps have to be used for determine the characteristic polynomial (based on Eq. 200): multiply the matrices by the constant $\lambda$, evaluate the sum of the multiplied matrices, and expand the determinant of it. Finally, we can collect the coefficients $a_{i}$ for the powers of $\lambda$. Instead of this method, Theorem 1, 
or Consequence lis applied. In this case, because the matrices are three dimensional, the characteristic polynomial is a sixth order polynomial, which is $p(\lambda)=a_{6} \lambda^{6}+a_{5} \lambda^{5}+\ldots+a_{0}$.

$$
\begin{aligned}
& p(\lambda)=\operatorname{det}\left(\lambda^{2} \mathbf{A}\right)+\operatorname{det}(\lambda \mathbf{B})+\operatorname{det}(\mathbf{C}) \\
& +\operatorname{tr}\left(\lambda^{2} \mathbf{A} \operatorname{adj}(\lambda \mathbf{B})\right)+\operatorname{tr}\left(\lambda \mathbf{B} \operatorname{adj}\left(\lambda^{2} \mathbf{A}\right)\right) \\
& +\operatorname{tr}\left(\lambda^{2} \mathbf{A} \operatorname{adj}(\mathbf{C})\right)+\operatorname{tr}\left(\mathbf{C} \operatorname{adj}\left(\lambda^{2} \mathbf{A}\right)\right) \\
& +\operatorname{tr}(\mathbf{C} \operatorname{adj}(\lambda \mathbf{B}))+\operatorname{tr}(\lambda \mathbf{B} \operatorname{adj}(\mathbf{C})) \\
& +\operatorname{tr}\left(\mathbf{C} \lambda^{3} \mathbf{L}_{A B}^{\mathrm{T}}\right) \\
& p(\lambda)=\lambda^{6} \operatorname{det}(\mathbf{A})+\lambda^{3} \operatorname{det}(\mathbf{B})+\operatorname{det}(\mathbf{C}) \\
& +\lambda^{4} \operatorname{tr}(\mathbf{A} \operatorname{adj}(\mathbf{B}))+\lambda^{5} \operatorname{tr}(\mathbf{B} \operatorname{adj}(\mathbf{A})) \\
& +\lambda^{2} \operatorname{tr}(\mathbf{A} \operatorname{adj}(\mathbf{C}))+\lambda^{4} \operatorname{tr}(\mathbf{C} \operatorname{adj}(\mathbf{A})) \\
& +\lambda^{2} \operatorname{tr}(\mathbf{C} \operatorname{adj}(\mathbf{B}))+\lambda \operatorname{tr}(\mathbf{B} \operatorname{adj}(\mathbf{C})) \\
& +\lambda^{3} \operatorname{tr}\left(\mathbf{C} \mathbf{L}_{A B}^{\mathrm{T}}\right) .
\end{aligned}
$$

If we know the matrices $\mathbf{A}, \mathbf{B}, \mathbf{C}$, the coefficient list of characteristic polynomial is

$$
\left[\begin{array}{l}
a_{6} \\
a_{5} \\
a_{4} \\
a_{3} \\
a_{2} \\
a_{1} \\
a_{0}
\end{array}\right]=\left[\begin{array}{c}
\operatorname{det}(\mathbf{A}) \\
\operatorname{tr}(\mathbf{B} \operatorname{adj}(\mathbf{A})) \\
\operatorname{tr}(\mathbf{C} \operatorname{adj}(\mathbf{A}))+\operatorname{tr}(\mathbf{A} \operatorname{adj}(\mathbf{B})) \\
\operatorname{det}(\mathbf{B})+\operatorname{tr}\left(\mathbf{C} \mathbf{L}_{A B}^{\mathrm{T}}\right) \\
\operatorname{tr}(\mathbf{A} \operatorname{adj}(\mathbf{C}))+\operatorname{tr}(\mathbf{C} \operatorname{adj}(\mathbf{B})) \\
\operatorname{tr}(\mathbf{B} \operatorname{adj}(\mathbf{C})) \\
\operatorname{det}(\mathbf{C})
\end{array}\right] .
$$

\section{Case study on three degrees-of-freedom damped os- cillator}

In applied mechanics, a basic example is a three Degrees-ofFreedom damped oscillator. In this mechanical model the three moving bodies are connected to each other with linear springs and viscous dampers. We assume frictionless ground during the motion. The mechanical model of the example can be seen in Fig. 1

The mechanical model presented in Fig. 1, can be represented eq. three-storey house. In this model the mass $m_{1}$ with the linear spring $k$ and the viscous damper $b$ represents the downstairs connected to the base. The masses $m_{2}$ and $m_{3}$ with the linear springs $k$ can be represented the first and second storeys. In this model $f$ denotes the external force, e.g. the suction effect of the wind.

The equation of motion in homogeneous case is

$$
\mathbf{A} \ddot{\mathbf{q}}+\mathbf{B} \dot{\mathbf{q}}+\mathbf{C q}=\mathbf{0}
$$

where $\mathbf{q}=\left[\begin{array}{lll}x_{1} & x_{2} & x_{3}\end{array}\right]^{\mathrm{T}}$ is the vector of generalized coordinates. In Eq. 24 the matrices A, B, C, i.e. the mass, viscous damping and stiffness matrices are

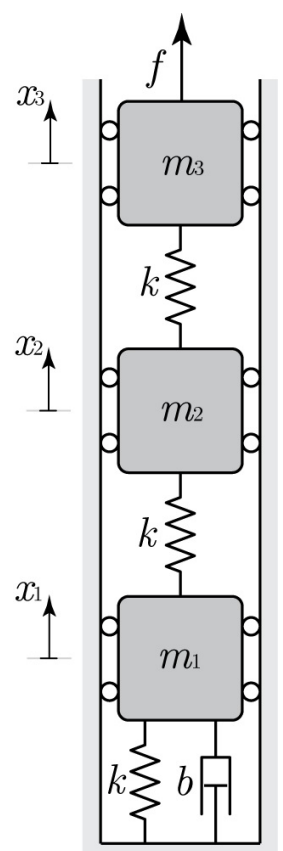

Fig. 1. The mechanical model of the three DoF damped oscillator

$$
\begin{aligned}
\mathbf{A} & =\left[\begin{array}{ccc}
m_{1} & 0 & 0 \\
0 & m_{2} & 0 \\
0 & 0 & m_{3}
\end{array}\right], \\
\mathbf{B} & =\left[\begin{array}{lll}
b & 0 & 0 \\
0 & 0 & 0 \\
0 & 0 & 0
\end{array}\right] \\
\mathbf{C} & =\left[\begin{array}{ccc}
2 k & -k & 0 \\
-k & 2 k & -k \\
0 & -k & k
\end{array}\right] .
\end{aligned}
$$

If we determine the characteristic polynomial as $p(\lambda)=$ $\operatorname{det}\left(\lambda^{2} \mathbf{A}+\lambda \mathbf{B}+\mathbf{C}\right)$, we multiply the matrices by the constant $\lambda$, evaluate the sum of constant multiplied matrices, and we expand the determinant of it. Finally, we can collect the coefficients $a_{i}$ for the powers of $\lambda$. The coefficients of characteristic polynomial are given in Eqs. 25 - 31. 


$$
\begin{gathered}
a_{6}=m_{1} m_{2} m_{3} \\
a_{5}=b m_{2} m_{3} \\
a_{4}=k\left(m_{1} m_{2}+2 m_{2} m_{3}+2 m_{1} m_{3}\right) \\
a_{3}=b k\left(m_{2}+2 m_{3}\right) \\
a_{2}=k^{2}\left(m_{1}+2 m_{2}+3 m_{3}\right) \\
a_{1}=b k^{2} \\
a_{0}=k^{3}
\end{gathered}
$$

If the coefficients (in Eq. (23) ) are compared to Eqs. 25) (31), it can be seen, that all elements are equal to each other. Therefore in application examples instead of the much algebraic calculation, the elements of characteristic polynomial can be given immediately in closed form by the coefficient list in Eq. (23).

\section{Conclusions}

Different matrix operations and calculation methods are studied in Linear Algebra courses. Matrix operations are also used in applied mechanical courses, e.g. in Basic Vibration courses during the calculation of natural angular frequency and vibration modes of multiple Degree-of-Freedom oscillators. In this paper the presented theorems or formulae to determine the characteristic polynomial can also be used in practices of Linear Algebra courses to calculate examples in alternative ways. It can also be applied in mechanical and civil engineering in problems from topic of designed structures against dynamical effect.

\section{References}

1 Bachrathy D, Mészáros I, Dynamical problems in interrupted high precision hard turning, In: LAMDAMAP: 9th International Conference and Exhibition on Laser metrology, machine tool, CMM and robotic performance; London, 2009, pp. 357-367.

2 Gálos M, Gyurika I G, Quality measuring numbers of milled edges of granite surfaces, Periodica Polytechnica Civil Engineering, 58(2), (2014), 121129, DOI 10.3311/PPci.2158

3 Srisanthi V G, Keshav L, Poorna Kumar P, Jayakumar T, Finite Element and Experimental Analysis of 3D Masonry Compressed Stabilised Earth Block and Brick Building Models against Earthquake Forces, Periodica Polytechnica Civil Engineering, 58(3), (2014), 255-265, DOI 10.3311/PPci.7443

4 Merczel D B, Somja H, Aribert J-M, Lógó J, On the behaviour of concentrically braced frames subjected to seismic loading, Periodica Polytechnica Civil Engineering, 57(2), (2013), 113-122, DOI 10.3311/PPci.7167

5 Jun L, Dafu X, Bingyan J, Random structural dynamic response analysis under random excitation, Periodica Polytechnica Civil Engineering, 58(3), (2014), 293-299, DOI 10.3311/PPci.7523

6 Axler S, Linear Algebra Done Right, 2nd Edition, Springer; New York, 1997.
7 Meyer C D, Matrix Analysis and Applied Linear Algebra, SIAM; Philadelphia, 2000.

8 Nicholson W K, Linear Algebra with Applications, 3rd Edition, PWS Publishing Company; Boston, 1995.

9 Tang K-T, Mathematical Methods for Engineers and Scientists 2, Springer; New York, 2007.

10 Wettl F, Lineáris Algebra (Linear Algebra), Typotex; Budapest, 2011. In Hungarian.

11 Budai Cs, Szilágyi B, About a Few Elegant Formulae in the Matrix Calculus, In: Matematikát, Fizikát és Informatikát Oktatók XXXVII. Országos Konferenciája; Miskolc, Hungary, August 26-28, 2013, pp. 25-30.

12 Budai Cs, Szilágyi B, Matrix Operations Applying Sum of Matrices, In: Matematikát, Fizikát és Informatikát Oktatók XXXVII. Országos Konferenciája; Miskolc, Hungary, August 26-28, 2013, pp. 1-4. in CD proceedings.

13 Inman D J, Vibration with Control, John Wiley \& Sons Ltd Press; Chichester, 2006. 